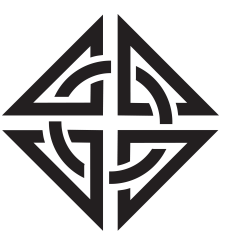

SCIENTIA
Sharif University of Technology

Scientia Iranica

Transactions A: Civil Engineering

http://scientiairanica.sharif.edu

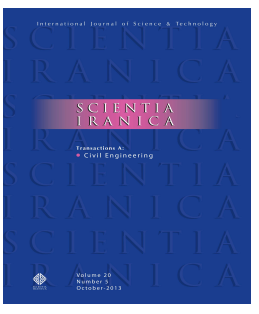

\title{
The effects of uniform magnetic field on the mechanical and microstructural properties of concrete incorporating steel fibers
}

\author{
M. Hajforoush ${ }^{a}$, A. Kheyroddin ${ }^{a}$, O. Rezaifar ${ }^{a}$, and M. Kioumarsi ${ }^{b}$,* \\ a. Department of Civil Engineering, Semnan University, Semnan, 35131-19111, Iran. \\ b. Department of Civil Engineering and Energy Technology, Oslo Metropolitan University, P.O. Box 4, St. Olavs plass N-0130 \\ Oslo, Norway.
}

Received 29 September 2020; received in revised form 22 April 2021; accepted 17 May 2021

\author{
KEYWORDS \\ Magnetic field; \\ Steel fiber-reinforced \\ concrete; \\ Compressive strength; \\ Splitting tensile \\ strength; \\ SEM image.
}

\begin{abstract}
The present study investigated the effects of applying a Uniform Magnetic Field (UMF) of flux density 500 mili Tesla (mT) to fresh and hardened concrete specimens with steel fibers at volume ratios of 1 and $1.5 \%$ on the mechanical and microstructural properties. To this end, compressive and splitting tensile strength tests were carried out on the specimens with Steel Fiber-Reinforced Concrete (SFRC) on Day 28. Furthermore, the microstructure of SFRC subject to the UMF was assessed using images taken by Scanning Electron Microscopy (SEM). An electromagnetic instrument, capable of generating a density of $500 \mathrm{mT}$, was used to produce UMF. Finally, a model equation was proposed to predict the splitting tensile strength of SFRC which was subject to the UMF as a function of its compressive strength. Application of UMF to SFRC specimens incorporating $1.5 \%$ steel fibers revealed an increase in both compressive and splitting tensile strengths up to about $18.2 \%$ and $9.5 \%$, respectively. The SEM analysis indicated that UMF enhanced the cement hydration process and it was responsible for the higher mechanical strength development of SFRC than the control specimen.
\end{abstract}

(C) 2021 Sharif University of Technology. All rights reserved.

\section{Introduction}

Concrete is a brittle material that needs to make a composite action with steel to compensate its low tensile strength [1-5]. Incorporating steel fibers into the concrete mixture is an applicable method for enhancing the energy dissipation of concrete [6,7]. In addition, steel fibers play a fundamental role in controlling the propagation of micro-cracks into the concrete under

*. Corresponding author.

E-mail addresses: mhajforoush@semnan.ac.ir ( $M$. Hajforoush); kheyroddin@semnan.ac.ir (A. Kheyroddin); orezayfar@semnan.ac.ir (O.Rezaifar); mahdik@oslomet.no (M. Kioumarsi)

doi: $10.24200 /$ sci. 2021.56888 .4963 tension and thermal stresses by the fiber bridging action [8-10]. This issue can be intensely developed when the alignment of steel fibers into concrete is in the perpendicular direction to the cracks $[11,12]$. For this purpose, researchers have suggested different methods for aligning the fibers into concrete materials [1315]. Among them, electromagnetic fields have been recognized as one of the simple approaches to aligning steel fibers into concrete as well as a base for producing a new type of orthotropic concretes $[16,17]$. In addition, magnetic fields can increase the electrical conductivity of concrete due to the linear arrangement of steel fibers in contact with each other $[18,19]$. Hence, this is a useful technique for different applications such as electromagnetic shielding and power system grounding [20]. Villar et al. [21] investigated the 
dynamic behavior of steel fibers in cement mortars subject to magnetic fields by means of an analytical model based on the Bingham model.

According to the literature, the application of a magnetic field to concrete mixing water could enormously improve the workability and mechanical properties of different types of concrete [22-25]. Given that water molecules can be considered as polar molecules with opposite ends of the molecule and opposite charges, the magnetic field could significantly influence the surface tension and other physical properties of water such as viscosity, temperature, electric conductivity, $\mathrm{pH}$, solubility, specific weight, and permeability pressure [26-29]. Gholhaki et al. [30] evaluated the effect of the properties of Self-Compacting Concrete (SCC) with magnetic water. The obtained results illustrated that the magnetic water enhanced the workability and mechanical strength of the concrete up to $8 \%$ and $18 \%$, respectively. This, in turn, resulted in water absorption content reduction by $10 \%$. In addition, a $45 \%$ reduction in the superplasticizer content was observed. Furthermore, the magnetic field treated water reduced the amount of cement by about $5 \%$ and improved the microstructure of the concrete by forming more C-S-H gel during the hydration process of cement; for more info refer to $\mathrm{Su}$ et al. [31,32].

According to previous studies, the mechanical properties of fresh concrete could increase by direct application of a magnetic field [33-40]. In a study conducted by Soto-Bernal et al. [33], the compressive strength of cement pastes exposed to weak magnetic fields was enhanced up to $13 \%$. In addition, the same results were reported in another experimental investigation conducted by Abavisani et al. [34], where applying a magnetic field to the concrete improved its mechanical strength up to about $17 \%$. Furthermore, the magnetizing technique could control the orientation of fibers in the intended direction and make an orthotropic concrete. Later, the effect of the magnetic field on the bending capacity of recycled mortar containing steel fibers was evaluated by Ferrández et al. [35]. The results indicated that the magnetic field could increase the bending capacity of mortar by $10 \%$. Recent research has also revealed that the magnetic field could improve the mechanical properties of the hardened concrete specimens as well. In this respect, Abavisani et al. [36] reported that applying a magnetic field to hardened concrete specimens increased their compressive strength by $8 \%$. As observed, hardened Reinforced Concrete (RC) beams exposed to a magnetic field could have a greater bearing capacity of about $7 \%$ than that of the reference beam [37]. Furthermore, an experimental investigation conducted by Rezaifar et al. [38] denoted that the compression behavior of HRC columns under magnetic field was improved by $11 \%$. Hajforoush et al. [39], in an experimental campaign, studied the mechanical properties of concrete containing steel fibers under a homogeneous magnetic field treatment. However, they did not investigate the microstructure properties of concrete specimens exposed to the magnetic field using microscopic images. In addition, the effects of magnetic field on the concrete specimens with different volume fractions of fibers and splitting tensile strengths of concrete were not addressed. According to their finding, magnetic field could increase the flexural and compressive strengths of concrete by about $16 \%$ and $18 \%$, respectively. Moreover, magnetic field caused a decrease in the permeable porosity and water absorption content of concrete by approximately $18 \%$ and $11 \%$, respectively, thus enhancing the durability of concrete in aggressive environments such as coastal and marine environments.

Application of a magnetic field in the concrete industry enjoys another advantage, i.e., consolidation of fresh concrete mixtures. Xue et al. [41] used the magnetic forces to vibrate cement mortar containing steel fibers. They found that the number of rotated fibers in mortar was greater than that of the same mortar vibrated by a shaking table. In addition, Abavisani et al. [36,37] demonstrated that the magnetic fields could be efficiently used for concrete vibration. In this regard, the movements formed by the magnetic field resulted from the existence of charged particles in sand and cement. The same observation was confirmed by Chen et al. [42]. According to the literature, there are a very limited number of studies on the mechanical properties of Steel FiberReinforced Concrete (SFRC) specimens exposed to magnetic fields. To the best of the authors' knowledge, no study has been conducted on the effect of applying a Uniform Magnetic Field (UMF) to fresh and hardened SFRC specimens containing different volume fractions of fibers on the microstructure properties. The present experimental campaign investigated the mechanical properties of SFRC with different volume fractions of steel fibers (1\% and 1.5\%). As observed in the previous studies $[11,14,21]$, incorporating steel fibers at different volume fractions to the fresh concrete can significantly affect the alignment of fibers, thus changing the mechanical strength of concrete at the age of 28 days. Meanwhile, Song and Hwang [6] illustrated that the compressive strength of concrete with the volume fractions of 1 and $1.5 \%$ exhibited the highest increase among other fractions. In addition, the microstructure of the SFRC subject to the UMF was evaluated through Scanning Electron Microscopy (SEM) imaging. Finally, an analytical equation was suggested to predict the splitting tensile strength of SFRC subject to the UMF with regard to results of their compressive strengths. The proposed equation was then compared to those recommended by ACI 
318-14 [43] and CEB-FIP [44] for plain concrete. To make UMF, a magnetic instrument capable of making the intended magnetic flux density was fabricated. As recommended and used by previous researchers [36-38], the magnetic flux density of about 500 mili Tesla (mT) was taken into consideration in this study.

\section{Materials and methods}

\subsection{Materials used}

In this experimental campaign, type-II Portland cement with a specific surface area of $3200 \mathrm{~cm}^{2} / \mathrm{g}$ and density of $3155 \mathrm{~kg} / \mathrm{m}^{3}$ was used in accordance with ASTM C150 [45]. Table 1 presents the chemical compositions of the used cement. The fine and coarse aggregates complying with the requirement of the ASTM C33 [46] were utilized where the density, water absorption, and maximum size of river sand used for the mix preparation were $2700 \mathrm{~kg} / \mathrm{m}^{3}, 1.4 \%$, and $6 \mathrm{~mm}$, respectively. Furthermore, the corresponding values for coarse aggregates (crushed gravel) were $2750 \mathrm{~kg} / \mathrm{m}^{3}$, $0.55 \%$, and $19 \mathrm{~mm}$, respectively. Table 2 presents the details of aggregates grading in accordance with the requirements of the ASTM C136 [47]. According to the ASTM C494 [48], a superplasticizer based on carboxylate was used in the experiments. Its specific density and $\mathrm{pH}$ were equal to $1150 \mathrm{~kg} / \mathrm{m}^{3}$ and 7.05 , respectively. As shown in Figure 1, the ferromagnetic

Table 1. Chemical compositions of type-II Portland cement.

\begin{tabular}{lc}
\hline Item & Cement (\%) \\
\hline $\mathrm{SiO}_{2}$ & 22.45 \\
$\mathrm{Al}_{2} \mathrm{O}_{3}$ & 4.85 \\
$\mathrm{Fe}_{2} \mathrm{O}_{3}$ & 3.95 \\
$\mathrm{CaO}$ & 64.86 \\
$\mathrm{MgO}$ & 0.8 \\
$\mathrm{SO}_{3}$ & 0.85 \\
$\mathrm{~K}_{2} \mathrm{O}$ & 0.51 \\
$\mathrm{Na}_{2} \mathrm{O}$ & 0.25 \\
$\mathrm{~L} . \mathrm{O} . \mathrm{I}$ & 1.48 \\
\hline
\end{tabular}

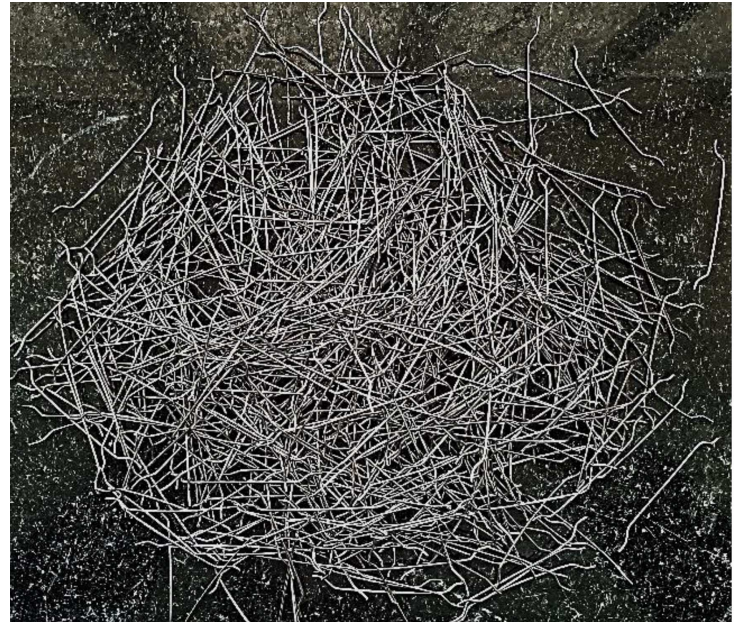

Figure 1. Steel fiber used in the study.

fibers were hooked-end steel fibers with the length and diameter of $50 \mathrm{~mm}$ and $0.8 \mathrm{~mm}$, respectively. The main characteristics of these fibers are given in Table 3 . The number of fibers in the mix design was based on the concrete volume (1\% and $1.5 \%$ ).

\subsection{Electromagnetic instrument employed in this study}

When an electric charge flows through an electromagnetic coil, the magnetic field is perpendicular to the plane of the coil, see Figure 2. Following this, Figure 3 illustrates that the electromagnetic coil used in this study included a loop of wire and a DC power source for producing the intended electric current. The magnitude of the magnetic flux density at the center of

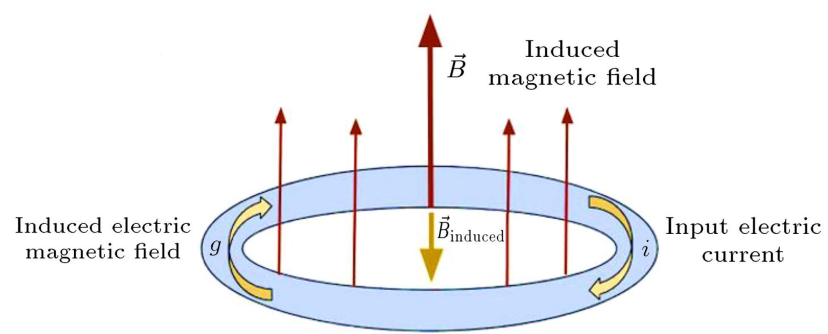

Figure 2. The direction of magnetic flux lines inside a coil.

Table 2. Sieve analysis of aggregates.

\begin{tabular}{lcccccccccc}
\hline Sieve size (mm) & 0.075 & 0.15 & 0.3 & 0.6 & 1.18 & 2.36 & 4.75 & 9.5 & 12.5 & 19 \\
Fine-aggregate passed (\%) & 1.5 & 6.9 & 17.2 & 30.7 & 52.8 & 81 & 95 & 100 & 100 & 100 \\
Coarse-aggregate passed (\%) & - & - & - & - & - & 1.7 & 22.39 & 93.26 & 99.9 & 100 \\
\hline
\end{tabular}

Table 3. Steel fibers characteristics.

\begin{tabular}{ccccccc}
\hline $\begin{array}{c}\text { Length } \\
(\mathbf{m m})\end{array}$ & $\begin{array}{c}\text { Diameter } \\
(\mathbf{m m})\end{array}$ & $\begin{array}{c}\text { Aspect ratio } \\
(\mathbf{l} / \mathbf{d})\end{array}$ & $\begin{array}{c}\text { Young's modulus } \\
(\mathbf{G P a})\end{array}$ & $\begin{array}{c}\text { Tensile strength } \\
(\mathbf{M P a})\end{array}$ & $\begin{array}{c}\text { Ultimate strain } \\
(\mathbf{\%})\end{array}$ & $\begin{array}{c}\text { Density } \\
\left(\mathbf{g} / \mathbf{c m}^{\mathbf{3}}\right)\end{array}$ \\
\hline 50 & 0.8 & 62.5 & 200 & 950 & 4 & 7.85 \\
\hline
\end{tabular}




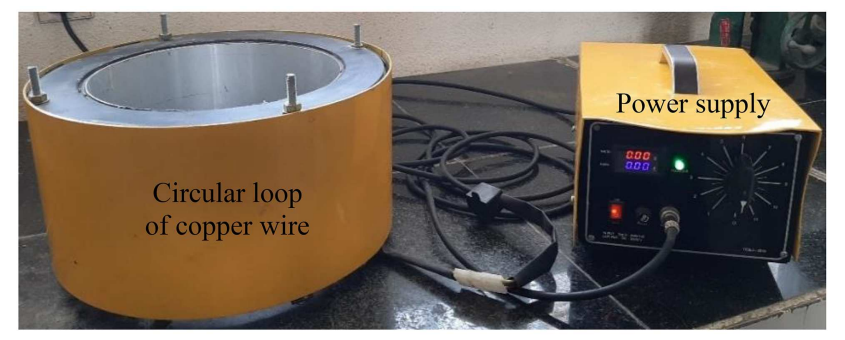

Figure 3. The electromagnetic instrument used in the present study.

an electromagnetic coil is determined by Eq. (1) [49]:

$$
B=\frac{\mu_{0} N I}{2 R},
$$

where $B$ is the magnetic flux density in Tesla $(\mathrm{T}), \mu_{0}$ the permeability of free space with the value of $4 \pi \times$ $10^{-7}$ T.m/A, $N$ the number of turns of wire, $I$ the electric current through the coil in Amperes (A), and $R$ the radius of coil in meters $(\mathrm{m})$.

In the electromagnetic instrument used in this study, the bobbin of the coil with a radius of $100 \mathrm{~mm}$ was manufactured using PVC plastic and wound with copper wires of $1.35 \mathrm{~mm}$. The electric current was employed to produce the intended magnetic field with an intensity of 7 Amperes produced by a 500-volt-ampere power supply. In order to decrease the temperature in the wires, pressman sheets were used among them. Finally, the strength of magnetic field in the coil was measured using a gauss meter where the intensity of $500 \mathrm{mT}$ was obtained from the instrument, as suggested by Abavisani et al. [34] and Rezaifar et al. [38] for magnetized concrete mixes.

\subsection{Mix design and tests methods}

The compressive and splitting tensile strength tests of SFRC subject to the UMF were conducted on $100 \mathrm{~mm}^{3}$ cubes and $100 \times 200 \mathrm{~mm}^{2}$ cylinders at the age of 28 days, respectively. To prevent magnetic leakage, all concrete molds were made up of PVC plastic with a thickness of $6 \mathrm{~mm}$. The average values for the five tested specimens were considered as the final value of each test. The SFRC specimens were categorized into four groups:

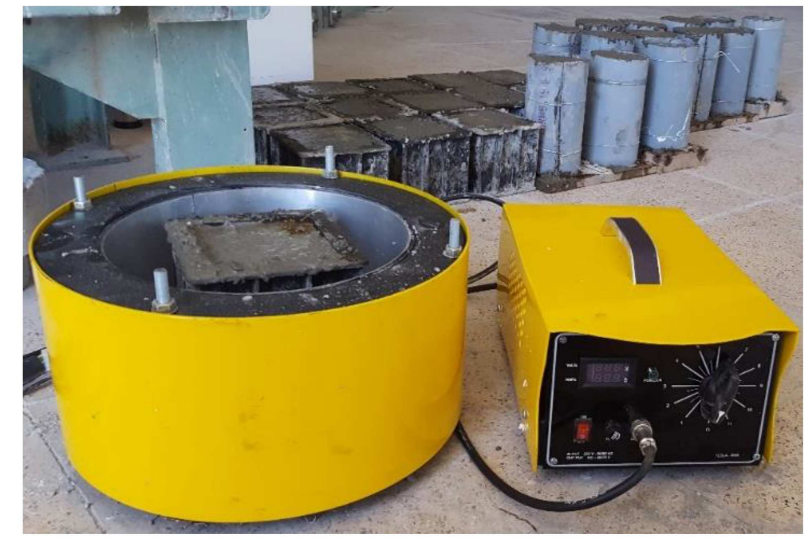

Figure 4. Magnetization of Pre-M specimens for $2 \mathrm{~min}$.

a) Control (Ctrl) specimens (with no fiber) which were not exposed to the UMF;

b) Non-Magnetized (Non-M) specimens (with $1 \%$ and $1.5 \%$ volume fractions of fiber) which were not subject to the UMF;

c) Pre-Magnetized (Pre-M) specimens (with $1 \%$ and $1.5 \%$ volume fractions of fiber) which were exposed to UMF until concrete is cast into the molds;

d) Post-Magnetized (Post-M) samples (with 1\% and $1.5 \%$ volume fractions of fiber) which were subject to UMF while the hardened concrete samples were examined at the age of 28 days.

Of note, the compressive strength test was performed on both Pre-M and Post-M specimens, while the splitting tensile strength test was only carried out on Pre-M specimens. To the authors' knowledge, pre-magnetizing concrete specimens can significantly improve the tensile strength of SFRC owing to the alignment of fibers in the concrete. Meanwhile, Post$M$ of the specimens has an insignificant impact on the mechanical strength of concrete, as reported by Abavisani et al. [36]. Finally, all Pre-M and Post-M specimens were compared to Non-M and Ctrl specimens. Table 4 presents the total characteristics of test specimens. As illustrated in Figure 4, the Pre$\mathrm{M}$ specimens were exposed to UMF for two minutes, as recommended by Hajforoush et al. [39], while the UMF was applied to Post-M samples during the test

Table 4. Total characteristics of test specimens.

\begin{tabular}{ccccc}
\hline Specimen name & $\begin{array}{c}\text { Steel fiber content } \\
(\boldsymbol{\%})\end{array}$ & $\begin{array}{c}\text { UMF } \\
(\mathbf{m T})\end{array}$ & $\begin{array}{c}\text { Performed test } \\
(\text { compression/tensile) }\end{array}$ & Number of specimens \\
\hline Ctrl & 0 & 0 & $\mathrm{C} / \mathrm{T}$ & 10 \\
Non-M & $1,1.5$ & 0 & $\mathrm{C} / \mathrm{T}$ & 20 \\
Pre-M & $1,1.5$ & 500 & $\mathrm{C} / \mathrm{T}$ & 20 \\
Post-M & $1,1.5$ & 500 & $\mathrm{C}$ & 10 \\
& & & & Total $=60$ \\
\hline
\end{tabular}




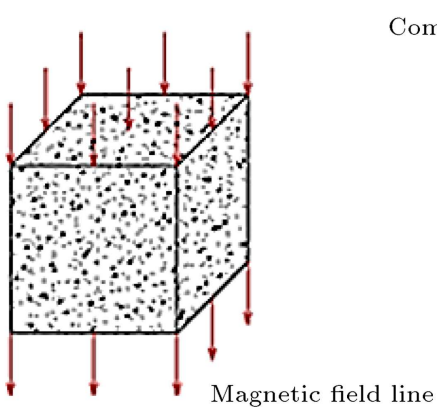

(a)

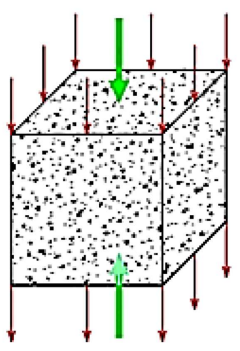

(c)

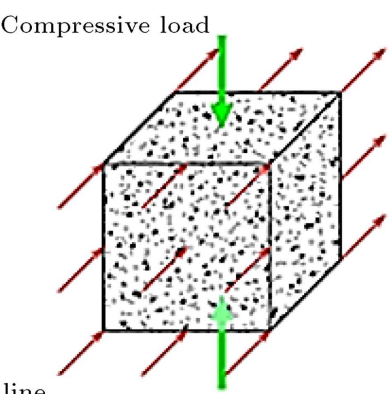

(b)

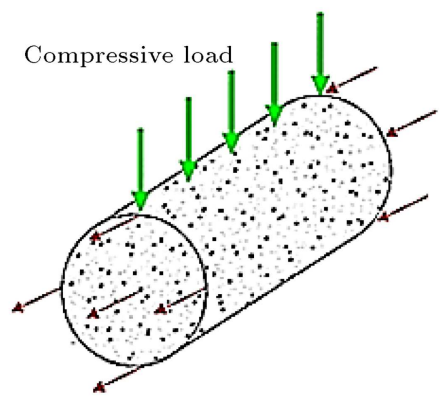

(d)

Figure 5. The schematic of the direction of the magnetic field applied to Pre-M and Post-M specimens: (a) The Pre-M specimen subjected to Uniform Magnetic Field (UMF) upon casting, (b) the direction of UMF applied to Pre-M specimen and compressive load in a comparison test, (c) the Post-M specimen exposed to simultaneous UMF and compressive load, and (d) the direction of UMF applied to Pre-M specimen and compressive load in tensile the test.

until collapse. The directions of UMF applied to Pre$\mathrm{M}$ and Post-M specimens are schematically shown in Figure 5. Figure 6 indicates the compressive strength test procedure for the Post-M specimens. To fulfill the objectives of this experimental study, the concrete mixtures were prepared, as illustrated in Table 5 . The mix design of SFRC was prepared in line with the ASTM C192 [50]. In the first step, the coarse and fine aggregates, in addition to one-third of the water volume, were introduced into the mixer. In the next step, the remaining mixing water (containing superplasticizer) and cement were added to the mixer. Then, steel fibers were added, in one- to two-minute long, into the mixer. The mixing process continued for three minutes. The concrete specimens were demolded after 24 hours. The specimens were cured under wet conditions until 28 days.

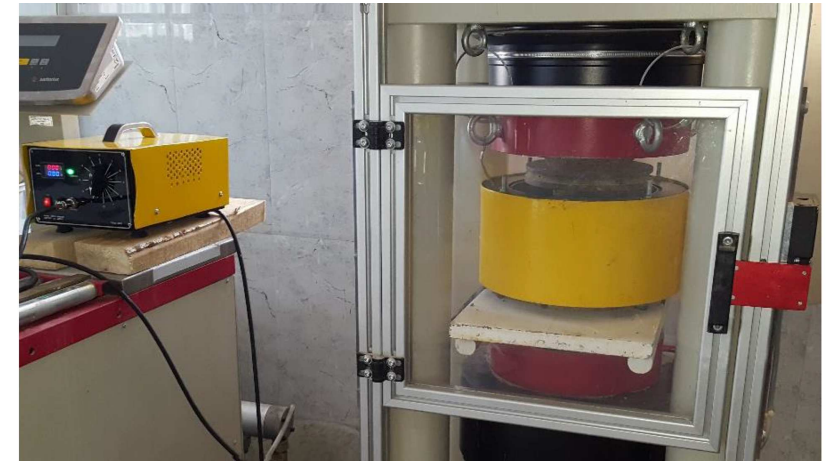

Figure 6. Concrete compressive strength test on the Post-M specimen exposed to the Uniform Magnetic Field (UMF).

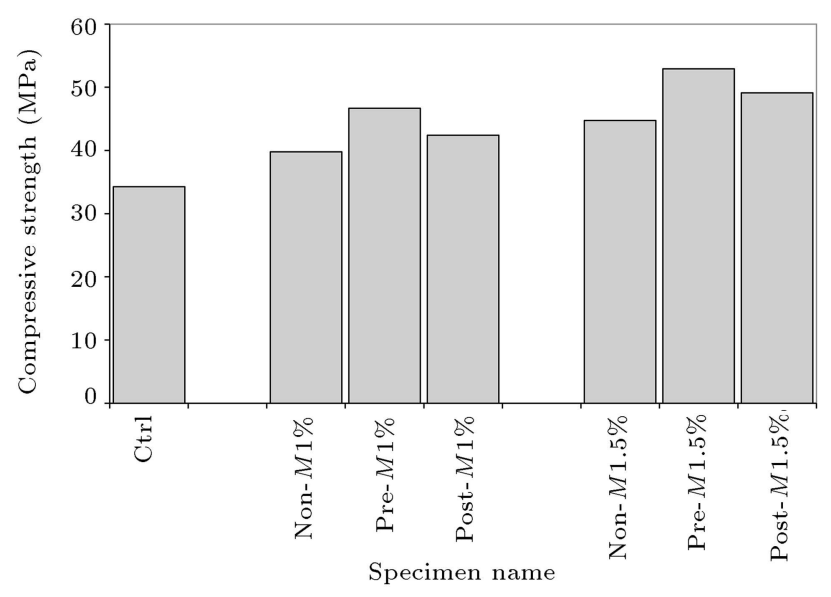

Figure 7. Compressive strength of $100 \mathrm{~mm}^{3}$ cubes for the Steel Fiber-Reinforced Concrete (SFRC) specimens under the application of Uniform Magnetic Field (UMF).

\section{Results and discussion}

\subsection{Compressive strength}

The obtained results of the compressive strength of SFRC specimens under the influence of UMF are given in Figure 7. According to this figure, the application of UMF to both fresh and hardened concrete samples increased their compressive strengths on the 28th day. Meanwhile, exposing fresh concrete to the UMF had a more denotative effect on its compressive strength. Despite the fact that the compressive strength of the Non-M specimen depended on its first crack strength, the Pre-M specimen could withstand the compressive load until failure. Following this, the alignment of steel fibers into the concrete mixture was shown to

Table 5. Mix proportion of Steel Fiber-Reinforced Concrete (SFRC) specimens.

\begin{tabular}{|c|c|c|c|c|c|c|c|c|}
\hline \multirow{2}{*}{$\begin{array}{l}\text { Cement } \\
\left(\mathrm{kg} / \mathrm{m}^{3}\right)\end{array}$} & \multirow{2}{*}{$\begin{array}{c}\text { Water } \\
\left(\mathrm{kg} / \mathrm{m}^{3}\right)\end{array}$} & \multirow{2}{*}{$\begin{array}{c}\text { Fine aggregate } \\
\qquad\left(\mathrm{kg} / \mathrm{m}^{3}\right)\end{array}$} & \multirow{2}{*}{$\begin{array}{c}\text { Coarse aggregate } \\
\qquad\left(\mathrm{kg} / \mathrm{m}^{3}\right)\end{array}$} & \multicolumn{2}{|c|}{ Superplasticizer } & \multicolumn{2}{|c|}{ Steel fiber } & \multirow{2}{*}{$W / C$} \\
\hline & & & & $(\%)$ & $\left(\mathrm{kg} / \mathrm{m}^{3}\right)$ & $(\%)$ & $\left(\mathrm{kg} / \mathrm{m}^{3}\right)$ & \\
\hline \multirow{2}{*}{450} & \multirow{2}{*}{202.5} & \multirow{2}{*}{801} & \multirow{2}{*}{890} & \multirow{2}{*}{0.9} & \multirow{2}{*}{4.05} & 1.0 & 78.50 & \multirow{2}{*}{0.45} \\
\hline & & & & & & 1.5 & 117.75 & \\
\hline
\end{tabular}


be perpendicular to the crack plane, where they could easily restrain the cracks through the fiber bridging action. Hence, the compressive strength of concrete samples was enhanced through the UMF. In addition, the compressive strengths of Pre-M and PostM samples with $1 \%$ of steel fibers were enhanced by $17.4 \%$ and $6.6 \%$, respectively, compared to Non-M sample. These amounts for the Pre-M and Post-M specimens at a fiber ratio of $1.5 \%$ were up to $18.2 \%$ and $9.7 \%$, respectively. The obtained results were in acceptable agreement with those reported by Abavisani et al. $[34,36]$ for fine aggregate concrete subjected to a magnetic field mainly because the effect of magnetic field on the concrete caused an increase in the C-S-H gel with a less porous and denser morphology during the process of hydration, thus leading to a reduction in the porosity value and consequently an increase in the compressive strength of concrete. Furthermore, the orientation of steel fibers in concrete samples subjected to UMF could significantly reduce the propagation of cracks in the concrete under compressive load. For the Pre-M specimen, as the applied UMF was in a perpendicular direction to the applied compressive load, fibers could better restrain the cracking of concrete. This finding agrees well with the results presented by Safari Tarbozagh et al. [51]. Inclusion of steel fibers at two volume fractions of $1 \%$ and $1.5 \%$ increased the compressive strength by $16.1 \%$ and $30.6 \%$, respectively, compared to the Ctrl specimen. According to Figure 7, increasing the steel fiber content resulted in an increase in the compressive strength of SFRC. In this regard, the compressive strengths of Pre-M and Post-M specimens increased up to $13.4 \%$ and $15.8 \%$ with the inclusion of $1 \%$ and $1.5 \%$ volume fractions of fibers, respectively.

As shown in Figure 8, there is a significant difference between the failure patterns of SFRC specimens under a compressive load in the presence of the UMF. It can be deduced that the compressive strength of the Non-M specimen depended on its first crack strength, where steel fibers could not have a remarkable effect on the compressive strength of concrete. However,

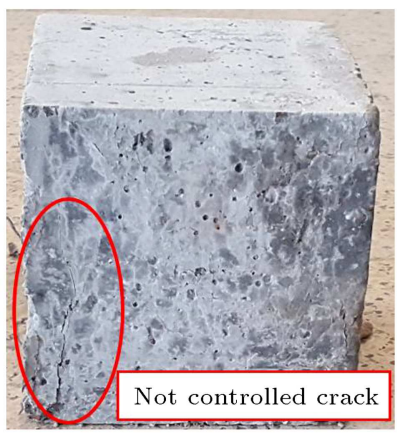

(a)

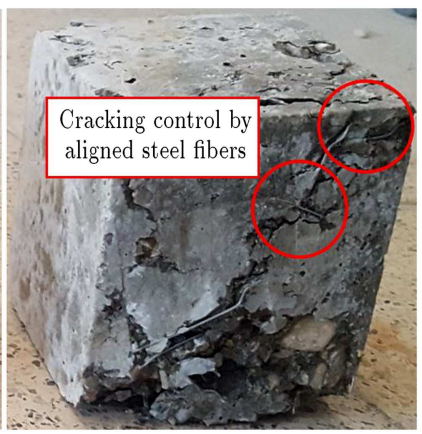

(b)
Figure 8. Two Steel Fiber-Reinforced Concrete (SFRC) specimens: (a) Non-M specimen and (b) pre-M specimen. under the application of UMF in the SFRC specimen, alignment of the fibers was perpendicular to the crack plane where they could strongly restrain the cracks through fiber bridging. Hence, steel fibers increased the compressive toughness of concrete and ultimate crack width. This result agrees well with that reported by Mudadu et al. [52] who evaluated the effect of fiber orientation on the post-cracking behavior of SFRC.

\subsection{Splitting tensile strength}

Figure 9 illustrates the results of splitting tensile strength of the SFRC specimens containing $1 \%$ and $1.5 \%$ steel fibers under the application of UMF. The tensile strength of the Pre-M specimen containing $1 \%$ volume fraction of steel fiber increased by $6.5 \%$ compared to the Non-M specimen. Furthermore, applying UMF to the fresh specimens with $1.5 \%$ steel fibers increased the tensile strength up to about $9.5 \%$. Upon increasing the temperature of the specimens under UMF, a molecular restructuring process observed in the specimens led to a reduction in the concrete porosity value. Moreover, the calcium hydroxide content, with the chemical formula $\mathrm{Ca}(\mathrm{OH})_{2}$, was reduced by imposing UMF on fresh concrete specimens. The UMF could transform the calcium hydroxide into calcium silicate hydrate gel; this is the main reason for the development of compressive and tensile strength of cementitious composites, thus resulting in improved bond strength between the steel fiber and hydration products. Therefore, the tensile strength of concrete while applying UMF was enhanced. This result agrees well with [33] for cement pastes under weak magnetic fields and also by Mu et al. [11] for mortar. Besides, the incorporation of steel fibers with the volume fractions of $1 \%$ and $1.5 \%$ into concrete increased its tensile strength to $16.4 \%$ and $24.9 \%$, respectively. According to Figure 8, it can be seen that increasing steel fiber

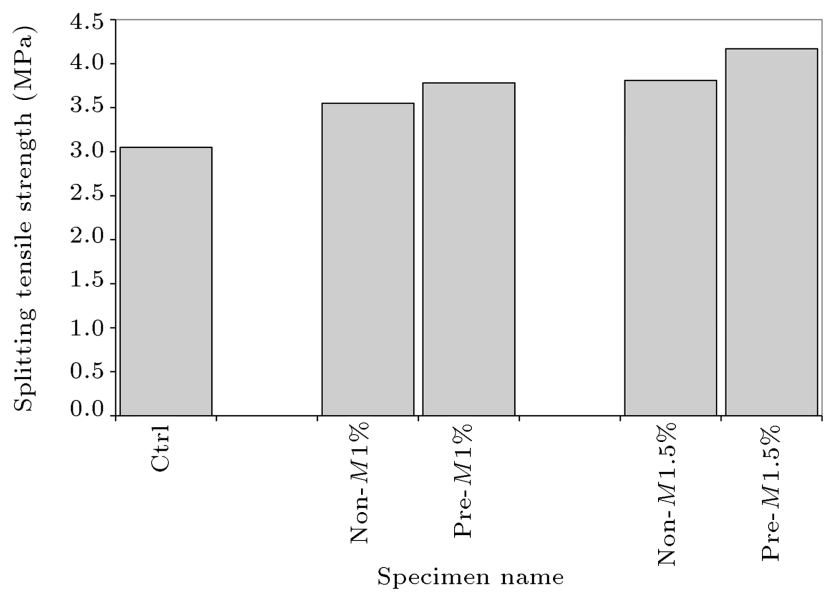

Figure 9. Splitting tensile strength of $100 \times 200 \mathrm{~mm}$ cylinders for the Steel Fiber-Reinforced Concrete (SFRC) specimens under the application of Uniform Magnetic Field (UMF). 
content in concrete led to an increase in its tensile strength. In this regard, the tensile strength of Pre$\mathrm{M}$ specimen increased by $10.3 \%$ due to increase in the steel fiber content from 0 to $1.5 \%$. The general trend for the tensile strength of concrete specimens was similar to what was observed for the compressive strength presented by Hajforoush et al. [26] and also by Gholhaki et al. [30] for SCC with magnetic water.

The correlation between the splitting tensile and compressive strengths of concrete specimens at the age of 28 days is given in Figure 10 . Following this, the equation of $f_{t}=0.65\left(f_{c}\right)^{0.5}$ was proposed to calculate the splitting tensile strength of concrete specimens (subjected to UMF) based on their compressive strength in which a high correlation coefficient of $R^{2}=0.94$ was observed by the curve fitting with the collected experimental data. The results calculated by this equation are very close to the values predicted by ACI 318-14 [43] and CEB-FIP [44] for plain concrete. The splitting tensile strength for a plain concrete with no UMF is calculated using Eq. (2) with respect to ACI 318-14 code [43]:

$$
f_{t}=0.55\left(f_{c}\right)^{0.5} \text {. }
$$

When the UMF is imposed on the fresh concrete samples, Eq. (2) can be modified into Eq. (3) as shown below:

$$
f_{t}=\sqrt{\alpha} 0.55\left(f_{c}\right)^{0.5} .
$$

The exposure of fresh concrete samples to the UMF caused the modification of $f_{t}$ by ACI 318-14 code [43] to $\sqrt{\alpha} f_{t}$, where coefficient $\alpha$ is proposed by 1.4 . In this investigation, as suggested by ACI 318-14 [43], the cube compressive strengths of SFRC samples were transformed to cylindrical ones $\left(f_{c}\right)$.

\subsection{Scanning Electron Microscopy (SEM) analysis}

The microscopic images of the Non-M and Pre-M specimens are given in Figure 11(a) and (b), respectively. According to this figure, there is a major difference between the amount and morphology of the $\mathrm{C}-\mathrm{S}-\mathrm{H}$ gel, which is the main hydration product of cement. The SEM analysis indicates that the UMF enhances the cement hydration process responsible for the higher mechanical strength development of SFRC than the control specimen. Application of UMF to fresh concrete provided a complete hydration process compared to the concrete with no magnetic treatment. The morphology of the gel became denser than the specimens with no UMF. This could be due to the molecular restructuring process in the hydration process of cement, which led to improvement of the quality of concrete subjected to the UMF. In addition, applying UMF to fresh specimens provided completed cement hydration compared to conventional concrete. The observed result is in good agreement with [33] for cement pastes. According to Figure 11, using a magnetic field increased the chemical reactions during the cement hydration. The reason is that the magnetic field created more crystalline phases in the crystallization process. The crystals, which shaped in the Non-M sample, contained several pores developed among the paste. Exposing fresh SFRC to the UMF reduced calcium hydroxide, which is responsible for the reduction of the mechanical strength of cementitious composites. Furthermore, the UMF could transform calcium hydroxide into the $\mathrm{C}-\mathrm{S}-\mathrm{H}$ gel during the hydration process of cement. This might be one main reason for the mechanical strength development of concrete under the application of the UMF.

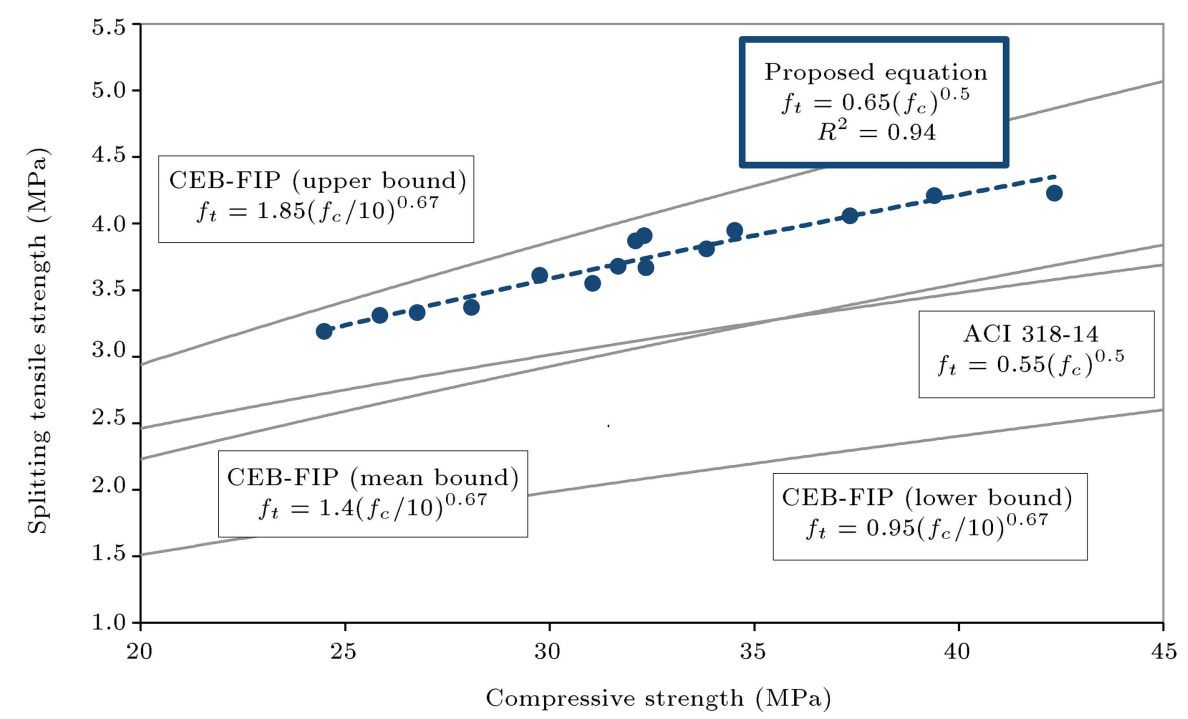

Figure 10. Variation of the compressive strength vs. splitting tensile strength for the Steel Fiber-Reinforced Concrete (SFRC) specimens under the application of Uniform Magnetic Field (UMF). 


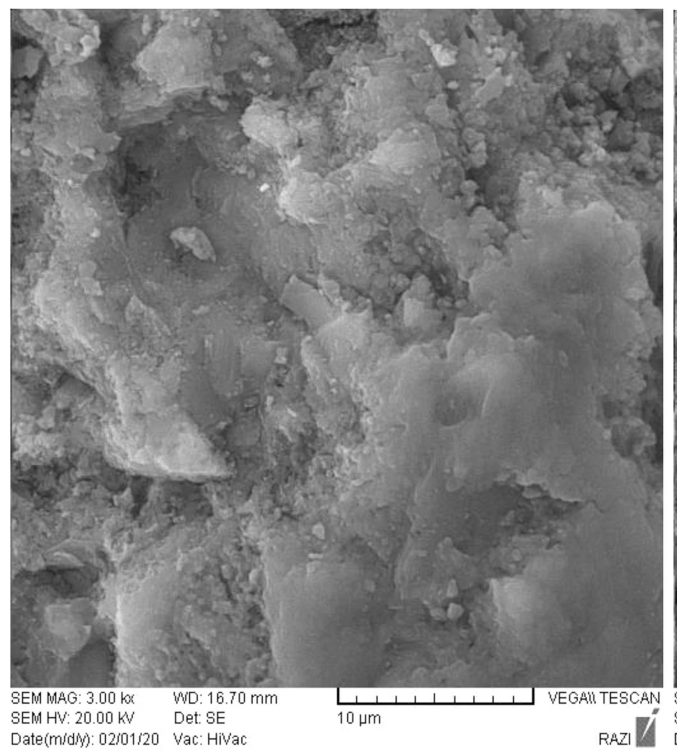

(a)

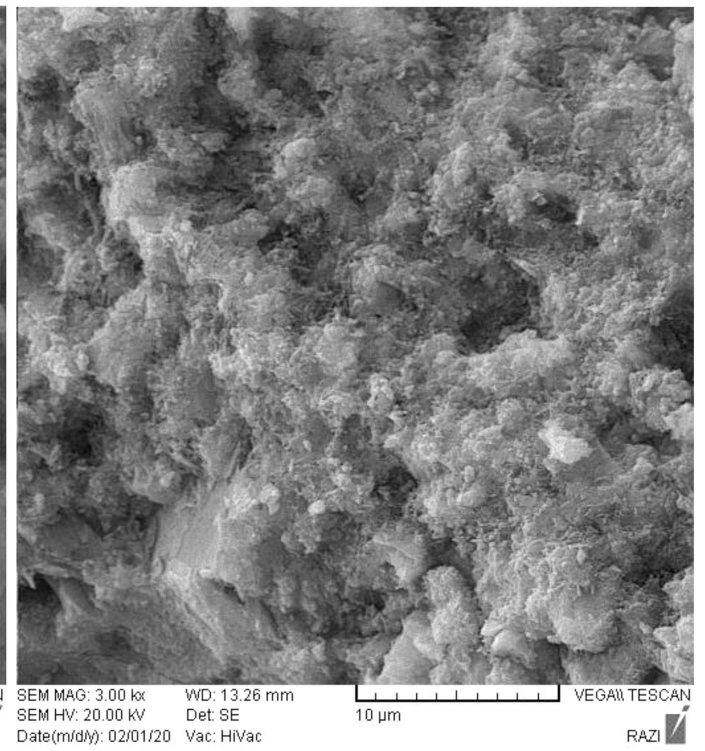

(b)

Figure 11. Microstructure of Steel Fiber-Reinforced Concrete (SFRC) by means of Scanning Electron Microscopy (SEM) imaging: (a) Concrete without magnetic treatment and (b) concrete with magnetic treatment.

\section{Conclusions}

In this study, the microstructural and mechanical properties of concrete samples subjected to Uniform Magnetic Field (UMF) of $500 \mathrm{mT}$ were evaluated considering different fiber contents ( $1 \%$ and $1.5 \%)$. Then, compressive and splitting tensile strengths tests were conducted on the Steel Fiber-Reinforced Concrete (SFRC) specimens under the application of UMF. In addition, the Scanning Electron Microscopy (SEM) test was employed to assess the microstructure of the samples under UMF exposure:

- Exposing fresh SFRC specimen to UMF (Pre-M specimen) increased its compressive strength at the age of 28 days up to $17.4 \%$ and $18.2 \%$ at the steel fiber content of $1 \%$ and $1.5 \%$, respectively;

- Compressive strength of SFRC specimen subjected to simultaneous compressive load and UMF (Post$\mathrm{M}$ specimen) was enhanced by $6.5 \%$ and $9.7 \%$ at the steel fiber content of $1 \%$ and $1.5 \%$, respectively;

- Applying the UMF to Pre-M specimen with steel fiber volume fractions of $1 \%$ and $1.5 \%$ increased their splitting tensile strengths at the age of 28 days up to $6.5 \%$ and $9.5 \%$, respectively;

- A strong correlation exists between the compressive strength and the splitting tensile strength of SFRC under the UMF. The equation of $f_{t}=$ $0.65\left(f_{c}\right)^{0.5}$ was proposed to estimate the splitting tensile strength of SFRC specimens exposed to the UMF with an acceptable correlation coefficient of $R^{2}=0.94$
- The SEM images demonstrated that the amount of $\mathrm{C}-\mathrm{S}-\mathrm{H}$ gel became more extensive in the presence of the UMF. Furthermore, the morphology of the gel became less porous and denser by applying the UMF. Thus, cement hydration products and their chemical reactions increased upon using the UMF.

\section{References}

1. Kazemi, M., Hajforoush, M., Talebi, P.K., Daneshfar, M., Shokrgozar, A., Jahandari, S., Saberian, M., and $\mathrm{Li}, \mathrm{J}$. "In-situ strength estimation of polypropylene fibre reinforced recycled aggregate concrete using Schmidt rebound hammer and point load test", Journal of Sustainable Cement-Based Materials, 9(5), pp. 1-18 (2020).

2. Madandoust, R., Kazemi, M., and Yousefi Moghadam, S. "Analytical study on tensile strength of concrete", Romanian Journal of Materials, 2(2), pp. 204-209 (2017).

3. Kazemi, M. and Courard, L. "Modelling thermal and humidity transfers within green roof systems: effect of rubber crumbs and volcanic gravel", Advances in Building Energy Research, pp. 1-27 (2020).

4. Kheyroddin, A., Hajforoush, M., and Doustmohammadi, A. "Numerical investigation of composite shear walls with different types of steel and concrete materials as boundary elements", Journal of Rehabilitation in Civil Engineering, 8(3), pp. 124-138 (2020).

5. Kazemi, M. and Courard, L. "Simulation of humidity and temperature distribution in green roof with pozzolana as drainage layer: Influence of outdoor seasonal weather conditions and internal ceiling temperature", 
Science and Technology for the Built Environment, 27(4), pp. 1-16 (2021).

6. Song, P. and Hwang, S. "Mechanical properties of highstrength steel fiber-reinforced concrete", Construction and Building Materials, 18(9) pp. 669-673 (2004).

7. Ahmadi, M., Kheyroddin, A., Dalvand, A., and Kioumarsi, M. "New empirical approach for determining nominal shear capacity of steel fiber reinforced concrete beams", Construction and Building Materials, 234, p. 117293 (2020).

8. Altun, F. and Aktaş, B. "Investigation of reinforced concrete beams behavior of steel fiber added lightweight concrete", Construction and Building Materials, 38, pp. 575-581 (2013).

9. Kazemi, M., Kafi, M.A., Hajforoush, M., and Kheyroddin, A. "Cyclic behaviour of steel ring filled with compressive plastic or concrete, installed in the concentric bracing system", Asian Journal of Civil Engineering, 21(1) pp. 29-39 (2020).

10. Baghban, M.H. and Mahjoub, R. "Natural kenaf fiber and LC3 binder for sustainable fiber-reinforced cementitious composite: A review", Applied Sciences, 10(1), p. 357 (2020).

11. Mu, R., Li, H., Qing, L., Lin, J., and Zhao, Q. "Aligning steel fibers in cement mortar using electromagnetic field", Construction and Building Materials, 131, pp. 309-316 (2017).

12. Li, H., Mu, R., Qing, L., Chen, H., and Ma, Y. "The influence of fiber orientation on bleeding of steel fiber reinforced cementitious composites", Cement and Concrete Composites, 92, pp. 125-134 (2018).

13. Rotondo, P.L. and Weiner, K.H. "Aligned steel fibers in concrete poles", Concrete International, 8(12), pp. 22-27 (1986).

14. Villar, V.P. and Medina, N.F. "Alignment of hookedend fibres in matrices with similar rheological behaviour to cementitious composites through homogeneous magnetic fields", Construction and Building Materials, 163, pp. 256-266 (2018).

15. Alberti, M., Enfedaque, A., and Gálvez, J. "On the prediction of the orientation factor and fibre distribution of steel and macro-synthetic fibres for fibrereinforced concrete", Cement and Concrete Composites, 77, pp. 29-48 (2017).

16. Wijffels, M., Wolfs, R., Suiker, A., and Salet, T. "Magnetic orientation of steel fibres in self-compacting concrete beams: Effect on failure behaviour", Cement and Concrete Composites, 80, pp. 342-355 (2017).

17. Liew, M.S., Nguyen-Tri, P., Nguyen, T.A., and Kakooei, S., Smart Nanoconcretes and Cement-Based Materials: Properties, Modelling and Applications, Elsevier (2019).

18. Du, J., Tang, C., Jia, B., Zhang, D., and Miao, Q. "Preparation and long-term stability study of steel fiber/graphite conductive concrete", In Key Engineering Materials, Trans. Tech. Publ., 680, pp. 361-364 (2016).
19. Wu, J., Liu, J., and Yang, F. "Three-phase composite conductive concrete for pavement deicing", Construction and Building Materials, 75, pp. 129-135 (2015).

20. Yehia, S., Qaddoumi, N., Hassan, M., and Swaked, B. "Conductive concrete for electromagnetic shielding applications", Advances in Civil Engineering Materials, 3(1) pp. 270-290 (2014).

21. Villar, V.P., Medina, N.F., and Hernández-Olivares, F. "A model about dynamic parameters through magnetic fields during the alignment of steel fibres reinforcing cementitious composites", Construction and Building Materials, 201, pp. 340-349 (2019).

22. Ghorbani, S., Gholizadeh, M., and De Brito, J. "Effect of magnetized water on the mechanical and durability properties of concrete block pavers", Materials, 11(9), p. 1647 (2018).

23. Esfahani, A.R., Reisi, M., and Mohr, B. "Magnetized water effect on compressive strength and dosage of superplasticizers and water in self-compacting concrete", Journal of Materials in Civil Engineering, 30(3), p. 04018008 (2018).

24. Ghorbani, S., Ghorbani, S., Tao, Z., De Brito, J., and Tavakkolizadeh, M. "Effect of magnetized water on foam stability and compressive strength of foam concrete", Construction and Building Materials, 197, pp. $280-290$ (2019).

25. Ghorbani, S., Sharifi, S., De Brito, J., Ghorbani, S., Jalayer, M.A., and Tavakkolizadeh, M. "Using statistical analysis and laboratory testing to evaluate the effect of magnetized water on the stability of foaming agents and foam concrete", Construction and Building Materials, 207, pp. 28-40 (2019).

26. Hajforoush, M., Madandoust, R., and Kazemi, M. "Effects of simultaneous utilization of natural zeolite and magnetic water on engineering properties of selfcompacting concrete", Asian Journal of Civil Engineering, 20(2) pp. 289-300 (2019).

27. Todeshki, A.R.S., Vanani, H.R., Shayannejad, M., and Askari, K.O.A. "Effects of magnetized municipal effluent on some chemical properties of soil in furrow irrigation", International Journal of Agriculture and Crop Sciences, 8(3), p. 482 (2015).

28. Baghban, M.H. "Water sorption of hardened cement pastes", Cement Based Materials, 10, p. 63 (2018).

29. Cai, R., Yang, H., He, J., and Zhu, W. "The effects of magnetic fields on water molecular hydrogen bonds", Journal of Molecular Structure, 938(1-3), pp. 15-19 (2009).

30. Gholhaki, M., Kheyroddin, A., Hajforoush, M., and Kazemi, M. "An investigation on the fresh and hardened properties of self-compacting concrete incorporating magnetic water with various pozzolanic materials", Construction and Building Materials, 158, pp. 173180 (2018). 
31. Su, N., Wu, Y.H., and Mar, C.Y. "Effect of magnetic water on the engineering properties of concrete containing granulated blast-furnace slag", Cement and Concrete Research, 30(4) pp. 599-605 (2000).

32. Su, N. and Wu, C.F. "Effect of magnetic field treated water on mortar and concrete containing fly ash", Cement and Concrete Composites, 25(7) pp. 681-688 (2003).

33. Soto-Bernal, J.J., Gonzalez-Mota, R., RosalesCandelas, I., and Ortiz-Lozano, J.A. "Effects of static magnetic fields on the physical, mechanical, and microstructural properties of cement pastes", Advances in Materials Science and Engineering, 2015, pp. 1-9 (2015).

34. Abavisani, I., Rezaifar, O., and Kheyroddin, A. "Alternating magnetic field effect on fine-aggregate steel chip-reinforced concrete properties", J. Mater. Civ. Eng., 30(6), p. 04018087 (2018).

35. Ferrández, D., Saiz, P., Morón, C., Dorado, M., and Morón, A. "Inductive method for the orientation of steel fibers in recycled mortars", Construction and Building Materials, 222, pp. 243-253 (2019).

36. Abavisani, I., Rezaifar, O., and Kheyroddin, A. "Alternating magnetic field effect on fine-aggregate concrete compressive strength", Construction and Building Materials, 134, pp. 83-90 (2017).

37. Abavisani, I., Rezaifar, O., and Kheyroddin, A. "Magneto-electric control of scaled-down reinforced concrete beams", ACI Structural Journal, 114(1) pp. 233-244 (2017).

38. Rezaifar, O., Abavisani, I., and Kheyroddin, A. "Magneto-electric active control of scaled-down reinforced concrete columns", ACI Struct. J., 114(5) pp. 1351-1362 (2017).

39. Hajforoush, M., Kheyroddin, A., and Rezaifar, O. "Investigation of engineering properties of steel fiber reinforced concrete exposed to homogeneous magnetic field", Construction and Building Materials, 252, p. 119064 (2020).

40. Javahershenas, F., Gilani, M.S., and Hajforoush, M. "Effect of magnetic field exposure time on mechanical and microstructure properties of steel fiber-reinforced concrete (SFRC)", Journal of Building Engineering, 35, p. 101975 (2021).

41. Xue, W., Chen, J., Xie, F., and Feng, B. "Orientation of steel fibers in magnetically driven concrete and mortar", Materials, 11(1) p. 170 (2018).

42. Chen, J., Wang, J., and Jin, W. "Study of magnetically driven concrete", Construction and Building Materials, 121, pp. 53-59 (2016).

43. A. Committee, 318-14, Building Code Requirements for Structural Concrete (ACI 318-14) and Commentary, American Concrete Institute, Farmington Hills, Michigan, USA (2014).

44. CEB-FIP "Diagnosis and assessment of concrete structures state of the art report", CEB Bull, 192, pp. 8385 (1989).
45. ASTM C150/C150M-19a, Standard Specification for Portland Cement, ASTM International, West Conshohocken, PA (2019).

46. ASTM C33/C33M-18, Standard Specification for Concrete Aggregates, ASTM International, West Conshohocken, PA (2018).

47. ASTM C136-01, Standard Test Method for Sieve Analysis of Fine and Coarse Aggregates, American Society for Testing and Materials (2001).

48. ASTM C494, Standard Specification for Chemical Admixtures for Concrete, Annual Book of ASTM Standards, American Society for Testing and Materials, West Conshohocken, PA, USA (2004).

49. Grant, I.S. and Phillips, W.R., Electromagnetism, 2nd Edn., Manchester Physics, John Wiley \& Sons (2008).

50. ASTM C192, Standard Practice for Making and Curing Concrete Test Specimens in the Laboratory, ASTM International, West Conshohocken. PA, USA (2018).

51. Safari Tarbozagh, A., Rezaifar, O., and Gholhaki, M. "Electromagnetism in taking concrete behavior on demand", Structures, 27, pp. 1057-1065 (2020).

52. Mudadu, A., Tiberti, G., Germano, F., Plizzari, G.A., and Morbi, A. "The effect of fiber orientation on the post-cracking behavior of steel fiber reinforced concrete under bending and uniaxial tensile tests", Cement and Concrete Composites, 93, pp. 274-288 (2018).

\section{Biographies}

Mohammad Hajforoush is a PhD student of Structural Engineering at Semnan University, Iran. He received his BS and MS degrees from University of Guilan, Iran. His research interests include concrete structures, experimental methods in structural engineering, and material properties controlling through novel methods. His $\mathrm{PhD}$ thesis is related to the effects of uniform magnetic field and electric current on concrete structures behavior.

Ali Kheyroddin is an Invited Visiting Scholar at the University of Texas at Arlington, Arlington, TX, and a Professor of Civil Engineering at Semnan University. He received his MS from Iran University of Science and Technology, Tehran, Iran and his PhD from McGill University, Montreal, QC, Canada. He was the Chancellor of Semnan University for 8 years. His research interests include analysis and design of reinforced concrete structures, concrete properties, tall buildings, rehabilitation of existing buildings, and design of earthquake-resistant buildings.

Omid Rezaifar is an Associated Professor at the Department of Civil Engineering, Semnan University. He received his BS from Semnan University and his $\mathrm{MS}$ and $\mathrm{PhD}$ from Amirkabir University of Technology (Tehran Polytechnic), Tehran, Iran. His 
research interest includes structural analysis using Finite Element Method (FEM), experimental methods in structural engineering, composite structures, structural optimization, damage detection stability analysis, and rehabilitation of structures and bridges.

Mahdi Kioumarsi is an Associate Professor at the Department of Civil Engineering and Energy Tech- nology, Oslo Metropolitan University (OsloMet), Oslo, Norway. He has more than fifteen years of experience researching on concrete, deteriorated concrete structures, fiber-reinforced concrete, and FE simulation and has published in the leading international conferences and journals. He did his PhD in Structural Engineering at Norwegian University of Science and Technology (NTNU) in Trondheim, Norway. 